\title{
Agricultural and food economics - a new journal for a changing world
}

\author{
Alessandro Banterle ${ }^{1 *}$, Andrea Marchini $^{2}$, Erik Mathijs $^{3}$, Carlo Russo $^{4}$ and Decio Zylbersztajn ${ }^{5}$
}

* Correspondence: alessandro. banterle@unimi.it

Full list of author information is available at the end of the article
Agricultural and Food Economics (AFE) is an on line peer-reviewed open-access journal supported by the Italian Association of Agricultural Economics (SIDEA) and published by SpringerOpen. This open access formula is an innovative and valuable opportunity for readers and authors who are interested in deepening their knowledge and keeping up to date on international agri-food policy and economic issues of the agricultural and food sector in a globalised world.

In a fast-changing world, research in agri-food economics faces the important challenge of balancing the need of quickly publishing papers with that of following the rigorous scientific method. This e-journal tries to fill this gap by publishing peer-reviewed research articles that are open-access, and thus accessible to users immediately and free of charge for readers.

AFE welcomes research articles from scholars and researchers from all over the world to publish problem-oriented, high quality and refereed papers. AFE seeks clearly written articles to promote insightful understanding of the current trends in the agri-food system.

AFE publishes only original articles from a wide variety of economic perspectives that address current and relevant issues related to the agricultural and food system. Published papers focus on applied analysis, the discussion of innovative results, and relevant policy and managerial implications. Theoretical and methodological papers should be accessible to the journal's variety of international readers. Qualitative papers and meta-analyses are welcome if they comply with the journal's rigorous standards.

Topics of specific interest of AFE include agricultural and food market analysis, agri-food firm management and marketing, organization of the agri-food chains, consumer behaviour, food quality and safety issues, economics of nutrition and food security, food and health economics, agri-food policy and trade, sustainable rural development, natural and marine resource economics, and land economics.

Papers for publication in AFE are selected through a peer review process to ensure soundness, originality, relevance, and readability. AFE adopts a double-blind peer review process to ensure independent assessment of the papers. Each paper, with no exception, is reviewed by at least two referees of different nationalities. Manuscripts that are not within the scope of the journal may be returned to the authors without a formal review.

The editorial board of AFE is composed, in addition to the editors in chief, by many internationally renowned economists that guarantee the high quality level of the papers published.

(c) 2013 Banterle et al.; licensee Springer. This is an Open Access article distributed under the terms of the Creative Commons Attribution License (http://creativecommons.org/licenses/by/2.0), which permits unrestricted use, distribution, and reproduction in any medium, provided the original work is properly cited. 
AFE publishes three types of papers:

- Research papers. Research articles are original contributions addressing relevant research questions. Key aims of research articles are to discuss new and interesting results of sound and rigorous scientific analysis and to disseminate new knowledge about the agri-food system. Research papers will be prevalent in AFE.

- Review papers. Review articles are summaries of recent insights in specific research areas within the scope of AFE. Key aims of reviews are to provide systematic and substantial coverage of mature subjects, evaluations of progress in specified areas, and/or critical assessments of emerging technologies.

- Short notes. Short papers discussing current issues of general interest in the agri-food system.

The advantages of publishing with us are:

- fast peer-reviewing process;

- quick publication after acceptance;

- large dissemination and visibility of the papers, as it is an open-access journal;

- increased probability of prompt citations.

AFE is Abstracted/Indexed in: Google Scholar, OCLC, Summon by Serial Solutions. As soon as possible, AFE will be indexed also in Scopus and Web of Science.

\section{Author details}

${ }^{1}$ Department of Economics, Management and Quantitative Methods, University of Milan, Milan, Italy. ${ }^{2}$ Department of Economics and Food Sciences, University of Perugia, Perugia, Italy. ${ }^{3}$ Bioeconomics Division, University of Leuven, Leuven, Belgium. ${ }^{4}$ Department of Economics and Law, University of Cassino and Southern Latium, Cassino, Italy. ${ }^{5}$ School of Economics, Business and Accounting, University of São Paulo, São Paulo, Brazil. 